\title{
"A Study of the Aging and Social Welfare in Asia"- Singapore \& Vietnam
}

\author{
Ryotaro KATSURA* \\ Vietnam-Japan University
}

*Corresponding Author: Ryotaro KATSURA, Vietnam-Japan University, Japan

\section{Why is Aging Now A Problem IN ASIA?}

When we consider the structure of the Asia population and the changes it is undergoing, we see that the problem of an aging population will have very important effects on the future of the continent. Specifically, it is clear that the processes of change are completely different from those in the Europe and the USA. Moreover, it is estimated that the average age of the Asian population will advance at a rate exceeding even the Japanese aging figures. The total population of Asia increased from 1.4 billion to 3.7 billion from 1950 to 2000 , a $1.9 \%$ rate of increase per year. On the other hand, in the same period the population of those people aged 65 and over underwent an explosive increase, from 60 million to 220 million, an annual rate of $2.6 \%$. This increase well exceeds the rate of expansion of the total population. The percent of aged people in the total population increased from $4 \%$ to $6 \%$ in the same period. However these figures have not yet reach the lower limit for the standard of an aged country, which is $7 \%$, as defined by the United Nations. When we look at the age figures for Asia, only East Asia with 7.7\% has reached or exceeded the 7\% lower limit. Countries can be classified into the three groups, in terms of advancing aging population levels. The first group is the New Industrial Economy Societies (NIES) that have undergone advancing urbanization and industrialization, like Japan, and decreases in the birth rate: they are Korea, Hong Kong, Taiwan, Singapore, and Israel. The 2nd group is made up of countries that will reach the criteria for an aging society soon: Thailand, Viet Nam, India, and Sri Lanka. The 3rd group consists of countries that are in the process of becoming aging societies: the Philippines, Bangladesh, and others. However, even countries that were not facing the aging problem in 2000 will face that problem in 2050, and there will be an increase in the number of countries in which the rate of aged citizens will be more than 20\%. East Asian countries will become "super aging societies" with a 30\% age figure. On the other hand, countries in Southeast Asia will have $15 \%$ ratio of age and countries in South and Central Asia will have a 10 to $15 \%$ ratio. Countries in West Asia will have a 5 to $20 \%$ ratio (See table 1).

\section{Current Status of Aging in Asia}

A generally held belief is that lowering death rates and the extension of the average lifespan are what lead to the graying of the population. However, the largest actual cause of this change is the lowering of the birth rate. The extension of the average lifespan in under-developed countries has been derived from the lowering of the death rates among babies rather than the lowering of the death rate among the middle-aged and elderly. The lowering of babies' death rates leads to an increase in the ratio of young in the population, so the average age of the entire population is lower. On the other hand, the lowering of the birth rate results in fewer young people, so the average age of the entire population becomes higher. In addition, even when the birth rate drops, the phenomenon of an aging population does not appear quickly. There is a time lag of 10 to 20 years before we see this growth in the number of aged. The length of this time lag depends upon not only upon the speed that the birth rate drops but also on the drop of the death rate and the differences in the initial conditions. Generally speaking, with a rapid drop in the birth rate, there is a rapid increase in aging of the population.

The interval that it takes for the aged rate to double from $7 \%$ to $14 \%$ indicates the aging speed of each country (see table 1). The period that it took for the aged rate to double was quite long in France (115 years) and less in England (47 years). However, the table shows that in Asian countries except Hong Kong the periods are shorter -- less than 30 years. Among the countries that had a fall in total birth 
rate to 3\% in 1970 -- Hong Kong, Korea, Taiwan, and Singapore -- Hong Kong reached an aged rate of 7\% earlier (1983), but the period it took for the aged ratio to double was longer than the other three countries, 33 years. This may have been caused by immigration from China. Asian countries changed their population styles from many births and deaths to few births and deaths, which resulted in a rapid advancement of aging of the population. Each country needs to cope with the issue of a large number of aged in economic, financial, and social terms.

Table1. Aging populations and aged ratios (1950 to 2050)

\begin{tabular}{|l|l|l|l|l|l|l|l|l|l|l|}
\hline \multirow{2}{*}{ Area, country } & \multicolumn{5}{|c|}{ Citizens 65 and over (1,000) } & \multicolumn{3}{c|}{ Ratio of citizens 65 and over in total } \\
& & \multicolumn{3}{|c|}{ populations. } \\
\cline { 2 - 14 } & 1950 & 1975 & 2000 & 2025 & 2050 & 1950 & 1975 & 2000 & 2025 & 2050 \\
\hline World & 130865 & 231182 & 419197 & 822876 & 1418742 & 5.2 & 5.7 & 6.9 & 10.5 & 15.9 \\
\hline Advanced area & 64034 & 112534 & 170744 & 260851 & 315507 & 7.9 & 10.7 & 14.3 & 21.0 & 25.9 \\
\hline $\begin{array}{l}\text { Under } \\
\text { developing area }\end{array}$ & 66831 & 118648 & 248453 & 582025 & 1103234 & 3.9 & 3.9 & 5.1 & 8.5 & 14.3 \\
\hline Asia & & & & & & & & & \\
\hline East Asia & 297516 & 100835 & 215947 & 474519 & 879630 & 4.1 & 4.2 & 5.9 & 10.0 & 16.8 \\
\hline China & 24851 & 40830 & 114662 & 243506 & 381372 & 4.5 & 4.7 & 7.7 & 14.7 & 24.0 \\
\hline Hong Kong & 49 & 237 & 723 & 194100 & 319262 & 4.5 & 4.4 & 6.8 & 13.4 & 22.9 \\
\hline North Korea & 336 & 579 & 1315 & 2484 & 4317 & 3.1 & 3.6 & 5.9 & 10.1 & 17.3 \\
\hline Japan & 4135 & 8790 & 21862 & 36070 & 40077 & 4.9 & 7.9 & 17.2 & 29.2 & 36.5 \\
\hline South Korea & 574 & 1273 & 3338 & 8812 & 14154 & 3.0 & 3.6 & 7.1 & 17.6 & 30.5 \\
\hline Southeast Asia & 6752 & 11428 & 24411 & 57393 & 126047 & 3.8 & 3.6 & 4.7 & 8.3 & 16.4 \\
\hline Cambodia & 118 & 199 & 376 & 965 & 2221 & 2.7 & 2.8 & 2.9 & 4.4 & 7.5 \\
\hline Indonesia & 3150 & 4410 & 10242 & 22642 & 49706 & 4.0 & 3.3 & 4.8 & 8.4 & 16.9 \\
\hline Laos & 49 & 81 & 184 & 393 & 1008 & 2.8 & 2.7 & 3.5 & 4.6 & 8.8 \\
\hline Malaysia & 309 & 457 & 934 & 2967 & 6227 & 5.1 & 3.7 & 4.1 & 8.9 & 15.7 \\
\hline Myanma & 578 & 1229 & 2191 & 4774 & 9658 & 3.2 & 4.1 & 4.6 & 8.0 & 15.0 \\
\hline Philippine & 718 & 1291 & 2670 & 7318 & 17836 & 3.6 & 3.1 & 3.5 & 6.7 & 14.0 \\
\hline Singapore & 24 & 93 & 287 & 1090 & 1383 & 2.4 & 4.1 & 7.2 & 22.2 & 30.5 \\
\hline Thailand & 637 & 1317 & 3319 & 8607 & 16590 & 3.2 & 3.2 & 5.4 & 11.7 & 21.5 \\
\hline Viet Nam & 1152 & 2329 & 4178 & 8536 & 21173 & 4.2 & 4.9 & 5.3 & 8.2 & 18.0 \\
\hline South Asia & 18582 & 33450 & 68325 & 153576 & 323606 & 3.7 & 3.8 & 4.6 & 7.3 & 13.1 \\
\hline Bangladesh & 1514 & 2644 & 4334 & 10989 & 28743 & 3.6 & 3.5 & 3.1 & 5.3 & 11.3 \\
\hline India & 11971 & 23749 & 50015 & 111975 & 221266 & 3.3 & 3.8 & 4.9 & 8.2 & 14.4 \\
\hline Nepal & 355 & 464 & 857 & 1816 & 4501 & 4.1 & 3.5 & 3.6 & 4.8 & 8.9 \\
\hline Pakistan & 2120 & 2385 & 5186 & 12022 & 29325 & 5.3 & 3.4 & 3.6 & 4.8 & 8.4 \\
\hline Sri Lana & 409 & 546 & 1249 & 3294 & 4809 & 5.5 & 4.1 & 6.7 & 12.9 & 22.7 \\
\hline
\end{tabular}

Note: Figures for 2025 and 2050 are mid-term estimates.

Data: United Nations (2003)

Source: Haruo Sagaza, 'Population changes and social and economic developments in Asia,' in Hirofumi Tanada "Fewer children and aged and social and economic development in Asia," issued by Waseda University Press on 2005.

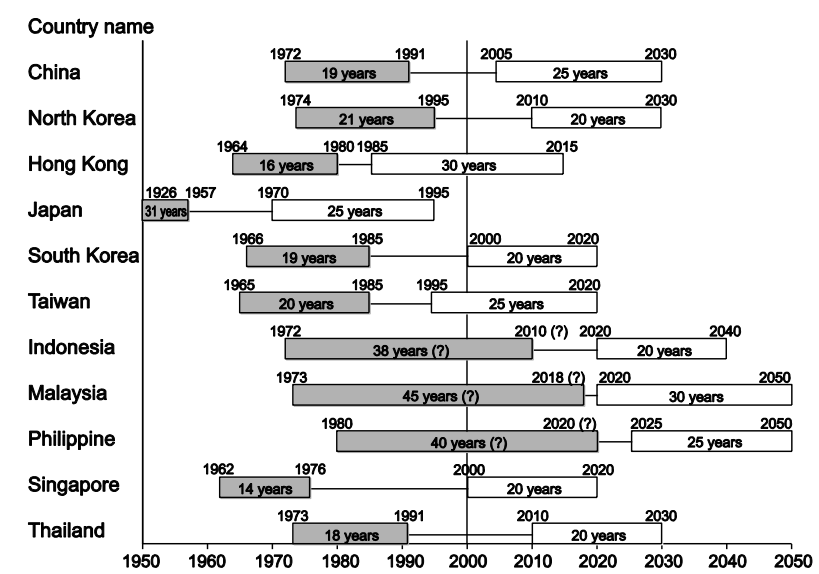

Figure1. Total birth rate change periods and aged ratio doubling periods in Asian countries 
Birth rate change period

(Total birth rate dropped from 5.0 to 2.1)
Aged ratio doubling period

(Ratio of aged 65 and over increased from $7 \%$ to $14 \%$ )

Source: Haruo Sagaza, 'Population changes and social and economic developments in Asia,' in Hirofumi Tanada "Fewer children and aged and social and economic development in Asia," issued by Waseda University Press on 2005.

\section{Graying Societies ANd Social Problems in ASIA}

When we look at types of families containing elderly people in Asian countries, where there are members older than 60, the percentage of three-generation families in 1996 was 36\% in Korea and $43 \%$ in Thailand. These figures are more than $7 \%$ higher than the figure for Japan. On the other hand, the percent of aged families containing only a couple and of aged people living alone were $30 \%$ and $14 \%$, respectively in Korea and $7 \%$ and $5 \%$ in Thailand. By the way, in the USA, the percentage of three-generation families was $2 \%$, of aged couples living alone was $35 \%$, and for aged people living alone was $40 \%$ in the same year. These figures show that there are great differences between the USA and Asian countries concerning family configuration.

Looking at the configuration by sex of aged persons living alone, single elderly females are overwhelmingly preponderant. In Korea, $6 \%$ of the elderly who were living alone were male, but $22 \%$ of elderly people who were living alone were female, more than triple of the male figure. This is because wives tend to outlive husbands in the spouse relational structure.

Asian elderly people generally live in traditional three-generation families at present, and a high value is place on parents and children living together. However, as in Japan, developing countries in Asia are losing three-generation families, due to advancing urbanization and industrialization. The number of aged couples and aged singles living alone are on the increase. Thus, the family structures there will change drastically. The number of single elderly woman is especially significant. It is presumed that Asian societies that modernize rapidly may be expected to suffer deterioration in the function of the family for supporting aged parents.

Asian countries are not as well endowed with comprehensive social security systems as the more advanced countries. Even countries with some system for supporting aged peoples have limitations on the range of applicability of these systems. The pension systems in Korea, Taiwan, Malaysia, and Singapore cover people in almost all types of economic activity. However, the pension systems in China and some other countries cover only public servants and employees of large enterprises in the formal sectors. The social security system in China is limited and applies only to employees of national governmental bodies, employees of government-managed enterprises, and urban workers. In agricultural communities, where approximately $70 \%$ of the Chinese population lives, aged people are generally supported by the family. In China, due to special population policies, the restrictions on moving from agricultural communities to urban areas, and the birth restriction policy (the single child policy), the urban areas are undergoing more rapid advancement of the graying of the population than are the agricultural communities. As indicated above, a variety of political and practical subjects related to aging will be highlighted as significant social problems.

\section{4. "PARENT CARE" in ASIA, WiTh EXAMPLeS FROM SingaPORE AND VieTnaM}

\subsection{Welfare for the Aged in Singapore}

Singapore was released from being a colony of England, recovered from earlier Japanese rule, and became independent of the Malaysia Federation in 1965. Now Singapore has grown to be a tourism and trade country that influences the world financial market. While it has an Asian feeling in terms of culture, it is in fact a complex and multi-national city made up of various races and nationalities. It is a country with a quite specific Asian social structure. Further, it is organized like a modern nation and has a reputation as an advanced modern urban nation, representing Asia both in name and reality. Nowadays, its Information Technology (IT) education extends even to elementary school students, yet the social welfare and social security budget occupies less than a mere $4 \%$ of the total national budget. We are very interested to understand how the pension assurance and caregiving insurance can be maintained with this small budget. In 1970, the population of those over 65 was a small $3.41 \%$. In 2001, it increased to $7.4 \%$. In 2015, the population of those over 64 will be $11.3 \%$ and soon thereafter $14 \%$. The average life expectancy was 76 for males and 80 for females in 2001 . This country may 
well be expected to experience more rapid urbanization and rapid aging than Japan. This small island of Singapore cannot be ignored in the study social security trends in the future Asia.

\subsection{1. "Family Values" Secure a "Family Service Policy"}

As a multi-racial nation, in order to respect each race's identity while attempting to achieve a broad social base for family policy, the national government has from an early stage been concerned with the existence of the family as a social unit, and tried various measures to improve family bases. Chinese Confucianism, Anglican Christianity, and Malaysian Islam served as the bases for this country's ideas about social security. These served to help develop the policies based on the understanding of different cultures and to strengthen the relationships among families.

\subsubsection{The "CPF (Central Provident Fund)" and "Maintenance of Parents Act" For Housing and Social Security}

One reason that Singapore developed into an advanced nation so early is that it had its Central Provident Fund (CPF), a well-organized "house holding system." This system may also be called a forced savings system for social security. Each member has to remit a specified part of each month's salary (20\% in principle) to his/her CPF account, and the employing company also must subscribe a certain amount for him/her. The person cannot withdraw any amount from this account freely. Although all of the money, including interest, belongs to him/her, it functions as social insurance for such items as housing, retirement, sudden illness, and a pension. It is said that Singapore residents have come to enjoy excellent public housing, matching each person's occupational level through the HDB (Housing \& Development Board), an improvement over the past very poor housing environment.

On another front, the parent support law is a system whereby parents over 60 , and parents below 60 with special circumstances such as illness, can claim from their children the support of living expenses if the child has sufficient economic allowance. When a claim is made, first an amicable settlement by an arbitration board is attempted. If the matter cannot be settled amicably, a tribunal will be held, and the court will make a decision. If the claim from parents is found to be appropriate, the court will order the children to pay the living expenses of the parents. Although the trial itself is closed, some cases may be opened to the extent that the discussions, processes, and decisions are public, although the names of the parties are not revealed.

This helps explain why the social welfare and social security budgets are such a small percent of the national budget; the government is neutral regarding problems of supporting aged parents and providing pensions. While maintaining that these problems are the responsibilities of families and family members, the government has also been improving local social policies, emphasizing housing, the environment, and personal relations, while establishing clear roles for the national government, local communities, and families.

\subsection{Welfare for the Aged in Vietnam}

\subsubsection{Why is it Important to Consider the Aged in Vietnam Now?}

I had been thinking of the problem of Messrs. Nguyen Viet and Duc (twins with congenital problems caused by the defoliant, Agent Orange), as a problem of caring for the handicapped. However, if we think deeply about the issue of providing care, it touches everyone's life, including the aged, and pertains to the dignity of life itself. Of course, in Vietnam lots of people who lived through the Vietnamese war are now reaching old age.

I have also been paying attention to the problem of the graying of the population in Vietnam. The first reason my attention turned to this problem is that I began to notice that the pace of graying in Vietnam is very much faster than it is in other Asian countries. The UN defines a society as "aging" if 7 to $14 \%$ of its population is 65 year old and over. (1) Then I noticed that looking at the future of Vietnam reveals important data for forecasting the future of other countries in Southeast Asia. The second reason I began to pay attention to the elderly in Vietnam is that their way of life represents "human life in war." It is true that the elderly of many countries have lived through wars, large and small. But, the elderly in Vietnam experienced one of the most miserable wars in history, the Vietnamese War. The third reason is that, though China receives a lot of attention due to its rapid economic growth, Vietnam is also undergoing rapid economic development within a socialism system, much like China. 
In other words, I am interested in how the elderly in Vietnam will live in a future that includes receiving medical services, health insurance, and elder care in a social system that has two aspects: capitalism in the economic sphere, and socialism in the political one. Lastly, I want to know how these issues relate to the daily lives, culture, and spiritual climate of the people in nations that have been supporting them.

\subsubsection{Outline of Vietnam and the country's spiritual climate}

Vietnam is a long and narrow country expanding north to south on the eastern edge of the IndoChinese peninsula. The two largest rivers in Southeast Asia flow to the sea: the Han River in North Vietnam and the Mekong River in South Vietnam. Both the north and south fall within the monsoon zone. The north is subtropical and the south is tropical. In the mountainous areas, where some minority races live, it is cold in the winter. That is, there are a variety of climates in Vietnam. The plains constitute a granary of various crops including rice, and constitute one of the best food producing regions in Southeast Asia. Therefore, the land has often been invaded by other nations. From ancient times, ethnic Vietnamese, represented by the Kinh, have been fighting to prevent a sustained invasion by China. In modern times the land, as a colony of France, was divided into plantations. In World War II, invasion by the Japanese army resulted in hunger being experienced by the populace. Some while after World War II, the U.S.A. invaded the nation, taking over from France. The Vietnamese War waged by the U.S.A. separated the land into North and South pursuant to the world's cold war structure. Both sides promoted misery and mired the country down in war. After the North Vietnamese army and the South Vietnamese National Liberation Front liberated South Vietnam, a civil war with Cambodia commenced and continued until 1989. As can be seen by this brief account, it is not too much to say that the history of Vietnam is a history of wars.

Vietnam recovered quickly economically, thanks to the "Doi Moi policy" that promoted economic capitalism within a socialist political framework. The U.S.-Vietnam Bilateral Trade Agreement (BTA) was signed in 2000, and Vietnam joined the WTO in 2007. Now, Vietnamese society is going to change drastically. However, this change will cause some gaps in Vietnamese society.

\subsubsection{Families and the Elderly in a Stream of Rapid Social Change}

I am of the opinion that five important gaps brought about rapid social change in Vietnam. These are the "gap between North and South," the "gap between urban cities and farm villages," the "gap between the Kinh race and the minority races," and the "gap between males and females." Recently, the gap between wealth and poverty is getting wider and wider even within the same poor farm village. The most basic group constituting society is "the family." Families in Vietnam are also changing rapidly. By so-called modernization, the bonds that tie families together and that hold people into local communities are becoming weak.

It is said that if we want to imagine a future Vietnam, we can see it clearly by paying attention to the shape of their families. The characteristics of Vietnamese families are also features of Asian families in general. The father-dominated or patriarchal system in Vietnam is influenced by Confucianism in China, and is resembled to those of other Asian countries. However, it is said that in some points the details of the Vietnamese system differ from those of China and other Asian countries. The difference is that the Vietnamese system incorporates equality between husband and wife. The family system in China emphasizes the relationship between parents and children (especially sons). Researchers say the relationship between husband and wife is very important in Vietnam. (2) Furthermore, in Vietnam, the elderly are very likely to live with family members. A recent research report stated that for all households, seniors living alone in Hanoi constituted 6.9\% and in Ho Chi Minh 4.8\%. The number of households in those cities after the war with couples with both spouses alive was $12.5 \%$ and $4.5 \%$, respectively. On the other hand, the percents of households with three generations living together were $57.4 \%$ and $51.0 \%$, respectively. So, more than half of the elderly in Vietnam were living with their married sons. (3) Perhaps, these figures are not very different today. The elderly in Vietnam very much wish to live with their families. There is another study that found that approximately $50 \%$ of the elderly are willing to live with their married sons, and approximately $10 \%$ the elderly are willing to live with their married daughters. In yet another study, examining farm villages, the elderly were found to be much more willing to live in extended families than urban people were. The Vietnamese social security system does not provide very much, so we might say that families are the most important group caring for the elderly. 


\subsubsection{The Traditional Sense of Values in Asia and the Power of the Elderly}

Vietnam may someday, as an underdeveloped country, experience changes in their social welfare system that are different from the process experienced in advanced countries like Japan. Namely, in the burst of rapid economic development after the Doi Moi policy, if we ask whether the government, the local community, or the family can cope with the trend toward fewer children and an aging population while maintaining a family style based on local communities and networks of relatives (clans) the answer could be that the issues may be very difficult to resolve. As you may learn by observing the result of the single-child policy in China, a socialist nation may find it difficult to reach a goal through government initiative. Dealing with the issues of many elderly and few children in Vietnam is certainly not a problem specific to Vietnam. This may be a destiny, which many Asian countries face.

So far, I have been studying the problem of the elderly in Asian countries, and found that the features in Asia are different from those in Europe and North America from various perspectives. The features of social change in Asia seem to have the following three characteristics. Since I started studying Asian society and culture, I have focused on three new keywords: "Rapid pace," "Gaps," and "Diversity." I already described the application of the former two words in themes related to aging and the gap between wealth and poverty. Now, let me describe here how diversity becomes an important keyword for considering the future of Asian welfare, and let's think together about what we should be learning from the elderly in Vietnam.

Asian countries have a variety of types of races, religions, and life styles that affect the management of daily life. Culture and society in each country is configured with multilayered and multiplexing tones based on these historical and social aspects. Vietnam is especially characterized by having areas with different cultural climates, with many minority races and a mixture of many religions. There is no other Asian country that has such clear diversity as Vietnam. In this country, the common cultural climates of Asia: the rice culture, bamboo culture, and tea culture, extend with the monsoon climate. Spiritual human ties to ancestors, nourished by territorial and blood bonds, exist there as various life styles, traditional ways of thinking, senses of value, and ways of apprehending life and death. These spiritual factors are firmly embedded in daily life in this modernizing society.

Taking care of parents, for example, it is a most difficult subject in Vietnam; how to maintain the traditional culture while recognizing the legitimacy of a variety of values and life styles, all the while attempting to harmonize socially provided care with private family care? In this context, it has become a feature of Vietnamese social welfare to simultaneously develop mutual support type social welfare centered on temples, on the one hand, and private fee-supported elderly homes for the wealthy living in urban areas, on the other.

Public homes for the elderly in Vietnam accommodate many poor seniors who have lost their relatives in war. Most of them are the widows of war heroes who contributed to victory in the Vietnamese War. On the other hand, South Vietnamese old people also once contributed to their country, and seniors who are still agile but who do not receive enough under the social security and pension systems care for their grandchildren, while themselves being cared for by their families. By participating actively in local festivals and temple events, they play their roles in their local community. Healthy old folks create health-maintenance and mutual support institutions, typical of a senior citizen's club, in each locality, and they try to convey the misery of war to the innocent young. Observing the things the elderly do in this country, I was much impressed by the strength of the elderly, having the patience and fortitude to keep on going that had been cultured by the Vietnamese War and Cambodian Civil War. We must learn how to live from these the old Vietnamese citizens!

\section{CONCLUSION}

This study looked at the current situations and problems of two Asian countries in terms of the issue of aging populations. It seems clear that the aging population problem is one of the important social problems to examine when considering the future of Asia. Yet, we cannot deny that each country has its own different cultural and social historical background, and that international trends (such as globalization) affect these countries as they advance.

However, this problem of aging populations surely and significantly will affect the future of Asian countries, and restrict the picture of the future for each country. From a demographic point of view, it 
is evident that Thailand and Singapore are facing large transitions. They cannot stop the change from many births and children to few births and children. Accordingly, the family size is being reduced. New family lifestyles, such as more common divorce, accelerate this reduction. The relationships among family members are changing. The shift of population results in changes in the family network. How each government develops care for the elderly in Asia in the future depends upon the conditions in each country. However, it is very important to observe how social and cultural statuses will develop specific to Asia, and how these relate to world trends. Examination of the aging population as it relates to future Japanese problems will more and more require shifting the view from the prevailing European social welfare styles to taking into account the results of changes in welfare for the elderly in Asia and the Pacific region.

\section{REFERENCES}

[1] Yasuko Hayase, "Asian populations - in globalization trends -" issued by the Institute of Developing Economy in 2004

[2] Reiko Yamato, 'The current situation of elderly care and the current generation's awareness of aging in Singapore' in "Gender Comparison Research in Asian Countries" research by Yasuko Miyasaka, representing the research team, Research result report of the Science Research Auxiliary Budget in 2001 to 2003, issued on 2004

[3] John Ang, "Aging and Social Welfare Policies in Singapore" (Supervised and translated by Ryotaro Katsura), issued by Kawashima Press in 1997

[4] Ryotaro Katsura, 'Singapore' in "Social Welfare Yearbook of the World 2002" edited by Yuichi Nakamura and others, issued by Shunpousha in 2002

[5] Jyun Katada, "Comparison of Cultures of Aging Societies" issued by Kyushu University Press in 2000

[6] Ryotaro Katsura "Features of Families in Vietnam and Welfare" ("Dynamically Changing Education and Welfare in Vietnam" written and edited by Manabu Kuroda et al., Bunrikaku, 2003)

[7] Le Ngoc Van 'Overview Research on the Vietnamese Family During Doi Moi' "Family and Women Studies" No 1 June 2002

[8] Bunro Fujimoto"Hoi thao huu nghi Viet-Nhat ve cham soc nguqi cao tuoi lan 1 nam 2006 Sol-2008 THONG TIN KHOC VA NGHIEP VU pp.104-105

[9] Ryotaro Katsura 'An Overview of Social Security for Long-Term Caring in Japan' "CHALENGE OF SOCIAL CARE IN ASIA", (ed.Tan Ngoh Tion, so on) Eastern University Press, Singapore, 2006 (English)

[10] Ryotaro Katsura 'What we can learn from the elderly in Vietnam- An integration of studies of social welfare, peace, and gerontology' " DIOXIN UNFORGETABLE RESPONSIBILITIY! VIET \& DUC AND WORLD PEACE” First News, 2013

[11] Ryotaro Katsura 'PEACE BUILDING: THE CHALLENGES OF AND PROSPECTS FOR A STEADYSTATE SOCIETY' "Social Science” Science Publishing Group, 7(1):1-6, 2018

\section{AUTHORS' BIOGRAPHY}

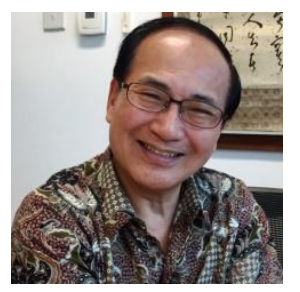

Prof. Ryotaro KATSURA is a Teacher of Master program on Public Policy in Vietnam-Japan University, HaNoi. Social Worker, Gerontologist and Peace Scientist.

Citation: Ryotaro KATSURA. ""A Study of the Aging and Social Welfare in Asia"- Singapore \& Vietnam". International Journal of Humanities Social Sciences and Education (IJHSSE), vol 5, no. 5, 2018, pp. 35-41. doi: http://dx.doi.org/10.20431/2349-0381.0505005.

Copyright: (C) 2018 Authors. This is an open-access article distributed under the terms of the Creative Commons Attribution License, which permits unrestricted use, distribution, and reproduction in any medium, provided the original author and source are credited. 